\title{
El diseñador-emprendedor. Comunicación de un perfil de egresado arquetípico en los sitios web de las universidades privadas argentinas
}

\section{The designer-entrepreneur. Communication of an archetypal graduate profile on the websites of Argentina's private universities}

\author{
Jonathan Alexis Taibo \\ taibojonathan@gmail.com \\ Universidad de Sevilla \\ Sevilla, España \\ ORCID: 0000-0003-3008-2206 \\ Recibido: 21 de octubre de 2020 \\ Aprobado: 03 de marzo de 2021 \\ Publicado: 01 de julio de 2021
}

Resumen:

Este artículo da cuenta de un proceso de investigación sobre la comunicación del perfil de egresado arquetípico en las universidades privadas de Argentina: el diseñador-emprendedor. El marco teórico aborda el surgimiento de las carreras de diseño en el país; la universidad en el contexto neoliberal y su legislación; el enfoque de educación por competencias; la semiótica de las pasiones y la teoría los arquetipos. La hipótesis a comprobar es que las universidades privadas argentinas ofrecen sus carreras de grado en diseño con una figura estereotipada del licenciado, basada fundamentalmente en el perfil de un diseñador-emprendedor en contraposición al diseñador-científico. El estudio - basado en el análisis de contenido de los sitios web de las carreras, llevado a cabo en enero de 2020 - arrojó, principalmente, la identificación de los arquetipos "el creador" y "el sabio", mismos que son puestos en discusión a partir de la adaptación del cuadrado semiótico de Greimas y su aplicación al análisis de dos spots publicitarios audiovisuales.

Palabras clave: diseño; universidad privada; diseñador; emprendedor; arquetipos; cuadrado semiótico de Greimas.
Abstract:

This article reports on the research process that investigates the communication of an archetypal graduate profile in the Private Universities of Argentina: the designer entrepreneur. The theoretical framework addresses the beginning of design degree courses in the country; the University in the neoliberal context and its legislation; the education through skills approach; the semiotics of passions and the theory of archetypes. The hypothesis to be tested is that private universities in Argentina offer their degree programmes in design with a stereotyped figure of the graduate, based fundamentally on the profile of a designer-entrepreneur as opposed to a designer-scientist. The study -based on the content analysis of the educational websites, carried out in January 2020 - showed, mainly, the identification of the archetypes "the creator" and "the sage", which are put into discussion at starting from the adaptation of the semiotic square of Greimas and its application to the analysis of two audiovisual advertising spots.

Keywords: design, private university, designer, entrepreneur, archetypes, Greimas semiotic square. 
Introducción En 1958, nació la primera carrera de diseño en Argentina, en la Universidad Nacional de Cuyo. Su origen fue estratégico, con un enfoque en el desarrollo y la activación de la economía regional. Luego, le siguieron la Universidad Nacional de la Plata (1963), con una clara influencia de las escuelas de Londres y Ulm, y el Instituto de Diseño Industrial en Rosario, en la misma década, que igualmente promovió los preceptos ortodoxos de "la buena forma". Por esa época, además, comenzó a extenderse la formación en el ámbito privado, como fueron los casos del Centro de Arte y Comunicación (CAYC) y de la Escuela Panamericana de Arte, que abordaban la enseñanza del diseño como comunicación visual (Devalle, 2008).

Sin embargo, el desarrollo y la expansión de las carreras de diseño en el ámbito universitario privado se daría en los años noventa, en el marco de un sistema de economía neoliberal.

\section{[...] a nivel global se estaba expandiendo el mercado de servicios, las economías nacionales se habían transnacionalizado y el valor de la marca había comenzado a reemplazar la anterior importancia que asumía el objeto. Era el momento de la reflexión en torno a las identidades institucionales, la cultura organizacional y los atributos que - en el plano de lo simbólico-descansaban sobre los objetos y, por sobre todo, sobre los servicios. (Devalle, 2008, p. 129)}

En este sentido, en el ámbito de la educación superior argentina, comenzaron a surgir algunas interrogantes (que fueron tomadas como antecedentes de esta investigación) en torno a la institucionalización de la disciplina, en un contexto académico y en una economía de mercado particular. ¿Qué implica la formación de un diseñador, con grado universitario, en una universidad privada? ¿En qué se diferencia de un egresado de una universidad pública? ¿En qué se distingue de un técnico egresado de un instituto superior no universitario? Estas preguntas se manifestaron entonces como punto de partida para delimitar el objeto de estudio del presente trabajo.

La importancia del análisis llevado a cabo en esta investigación, radica en poner en evidencia y en discusión los modos en que se comunica y se construye la figura del diseñador con formación académica de grado universitario, en el ámbito educativo privado, analizado en enero de 
2020. Es decir, las caracterizaciones que se hacen y los estereotipos que se crean o recrean del mismo en el discurso publicitario con el que se ofertan las distintas carreras.

Por último, esta investigación podría sentar un precedente para futuros análisis abordando, por ejemplo, otras carreras superiores donde la universidad privada esté disputando un espacio de legitimación frente a la universidad pública (y viceversa).

\section{Marco teórico y estado de la cuestión}

\section{La universidad y el contexto neoliberal}

La universidad puede ser tomada como un sinónimo de empresa en el contexto neoliberal. Al considerársele como una unidad de producción, la educación se convierte en un insumo y los alumnos, en productos finales que deben colocarse en el mercado. La demanda de la educación se regula de forma libre entre los intereses particulares de quienes desean formarse y lo que el mercado laboral necesita en cada momento particular. Las casas de altos estudios no tienen otros fines sociales que no sean los de preparar mano de obra calificada (Scotto, 2004). De esta forma, queda clara la influencia que tendrá el sistema productivo sobre qué temas se propone enseñar o investigar. Entonces, bajo este paradigma:

\section{La investigación no se encuentra entre los objetivos primarios de la universidad. Los costos más onerosos y los resultados más o menos intangibles, inciertos y mediatos de la investigación, hacen reco- mendable priorizar sólo aquellas áreas que puedan proporcionar re- sultados concretos, aplicables y a corto plazo. (Scotto, 2004, p.14)}

Cabe mencionar que en contraposición a este escenario, entendemos la existencia de otro paradigma donde la universidad busca formar científicos y donde, siguiendo a Hidalgo (2001, citado en Scotto, 2004), "el rol de la universidad pública es educar, producir incesantemente conocimientos a través de la investigación y transferir ciencia, tecnología y cultura al tejido social" (pp. 17-18).

\section{Legislación y terminología}

El debate sobre la Ley de Educación Superior Nº 24.521 (1995) planteó que la enseñanza superior estaría a cargo de las universidades nacionales, provinciales y privadas (reconocidas por el Estado Nacional) y por los institutos universitarios estatales o privados reconocidos, todos los cuales integrarían el Sistema Universitario Nacional. Esta Ley sufrió varias modificaciones con el correr de los años años ${ }^{1}$ hasta que

\footnotetext{
${ }^{1}$ Estas modificaciones están expresadas en el cuerpo del documento legal, que puede recuperarse de http://servicios.infoleg.gob.ar/infolegInternet/anexos/25000-29999/25394/texact.htm [Consultado por última vez el 17 de febrero de 2020].
} 
se promulgó una revisión que consideramos sustancial porque determinó las competencias de la universidad con respecto al Régimen de Títulos (y que es de relevancia para la comprensión terminológica del planteamiento de esta investigación). Así, en el Artículo 40 de la Ley de Educación Superior No 26.002 (2004) se especifica que "corresponde exclusivamente a las instituciones universitarias otorgar el título de grado de licenciado y títulos profesionales equivalentes, así como los títulos de posgrado de magister y doctor...".

Es importante entender que en el enunciado hay una clara diferenciación entre título de grado universitario y títulos profesionales equivalentes. Sobre este aspecto, Mónica Marquina (2004) aporta terminología clave, de la cual recuperamos los conceptos de grado, título (perfil de título y alcances de título), perfil de egresado y reconocimiento oficial de títulos. De manera relevante, aporta también la clasificación según el tipo de regulación estatal, donde hallamos dos grandes subgrupos: profesiones reguladas (contemplan las profesiones que en su ejercicio pudieren poner en riesgo de forma directa la salud, la seguridad, los derechos, los bienes o la formación de los habitantes; así el Estado regula su carga horaria mínima, contenidos curriculares, prácticas y que las carreras deban acreditarse periódicamente a través de la $C O N E A U^{2}$ ); por otro lado, se encuentran las profesiones no reguladas, títulos para profesiones que en su ejercicio no comprometen el interés público, a las cuales se les exige sólo una carga horaria mínima como único parámetro de regulación por parte del Estado.

En este sentido, se especifica que las carreras de grado son las que conducen al título de licenciado o equivalentes (médico, abogado, ingeniero, arquitecto, etc.) - que sólo pueden ser otorgados por instituciones universitarias-, desarrolladas en un mínimo de cuatro años y con una carga horaria mínima de 2600 horas reloj en modalidad presencial (Marquina, 2004).

Un último aspecto a detallar, luego de esta delimitación terminológica, es que las denominaciones de los títulos no están reguladas: las casas de altos estudios proponen el nombre de las carreras al momento de solicitar su reconocimiento oficial ante el Ministerio de Educación.

Esta situación puede ser explicada en función de la poca claridad por parte de las universidades respecto de la idea de "Perfil y alcance del Título" que implícitamente debieran llevar las denominaciones al momento de creación de una carrera y su respectiva titulación. Los términos utilizados en las denominaciones de los títulos no debieran ser el resultado de una combinación aleatoria, sino que debieran llevar implícito el "saber" y el "saber hacer". (Marquina, 2004, p. 20)

\footnotetext{
2 Comisión Nacional de Evaluación y Acreditación Universitaria: https://www.coneau.gob.ar/ [Consultado por última vez el 17 de febrero de 2020].
} 


\section{Saber, saber hacer, saber ser}

Superada la instancia de toma de conciencia crítica respecto al espacio tiempo en el que surgen las carreras de diseño dentro de las universidades privadas en Argentina, es pertinente mencionar que la presente investigación está amparada también por teorías en el paradigma constructivista. En tanto reflexión epistemológica, se hará un análisis de la realidad que se sabe construida por mecanismos de interacción social, en los que entran en juego subjetividades para la creación y el desarrollo de persuasión y representación (Ramos, 2017).

En este andamiaje, se sitúa el enfoque de la educación denominado en competencias, según el cual los alumnos van desarrollando la capacidad de abordar el mundo en sociedad de forma responsable a partir de la interdisciplina con que se estructuran los contenidos de las asignaturas. Esta perspectiva contempla el desarrollo integral de la persona, pues va más allá del concepto de saber y saber hacer, e incluye la idea de saber ser (Álvarez Morán et al., 2008).

En el Marco de Referencia Europeo, según la Recomendación del Parlamento Europeo y del Consejo de 18 de diciembre de 2006 sobre las competencias clave para el aprendizaje permanente:

\section{[...] las competencias se definen como una combinación de cono- cimientos, capacidades y actitudes adecuadas al contexto. Las com- petencias clave son aquellas que todas las personas precisan para su realización y desarrollo personales, así como para la ciudadanía activa, la inclusión social y el empleo. (18 de diciembre de 2006)}

\section{El espíritu emprendedor}

Es pertinente para este trabajo recuperar también el concepto de espíritu emprendedor - catalogado como una de las competencias básicas en el documento Hacia un enfoque de la educación en competencias y vinculado al contexto neoliberal que se describió con anterioridad-:

\section{El espíritu emprendedor tiene un componente activo y otro pasivo: la capacidad para provocar cambios y la habilidad para aceptar y apoyar cambios producidos por factores externos. El espíritu em- prendedor incluye la aceptación del cambio, asumiendo la respon- sabilidad de las propias acciones (positivas o negativas) marcando objetivos y alcanzándolos y teniendo motivación para lograr el éxi- to. (Álvarez Morán, et al. 2008, p. 24)}

\section{La pasión y el hacer}

Para incorporar una visión que ponga en cuestionamiento el enfoque por competencias, intentando comprender el motor que impulsa a los sujetos a hacer más allá de los fines de éxito económico, se recuperarán también 
conceptos desarrollados por la epistemología de las pasiones. Para Greimas y Fontanille (2002) el concepto de objeto de valor implica "un objeto que da un «sentido» (una orientación axiológica) a un proyecto de vida y un objeto que encuentra su significación en la diferencia, por oposición a otros objetos" (p.42). Así, podremos hacer un esfuerzo por reconocer y relacionar términos que se definan a partir de la contrariedad, la contradicción y la implicación (cuadrado binario de Greimas). Se entiende que el análisis de la estructura elemental busca descubrir unidades mínimas de significación y, a partir de allí, "conjuntos significantes cada vez mayores" (Zecchetto, 2002, p.222).

Los autores también desarrollan la noción de pasión del sujeto como resultado de un hacer y entienden a esta pasión como un acto del lenguaje:

[...] el hacer del sujeto apasionado no deja de recordar el del sujeto discursivo, al que dado el caso puede sustituir; es entonces cuando el discurso pasional, encadenamiento de actos patémicos, interfiere con el discurso que lo acoge - la vida en cuanto tal, de alguna manera-, lo perturba e influye. (Greimas y Fontanille, 2002, p.48)

\section{Teoría de los arquetipos}

Esta teoría se refiere a la desarrollada originalmente por Carl G. Jung, médico psiquiatra y psicólogo suizo, en la cual propone que existe una repetición constante de patrones, caracteres o energías en los sueños de las personas. También extiende este fenómeno a los mitos que se reproducen a través del tiempo en las diferentes culturas. Es decir, que no se trata de un fenómeno aislado, sino histórico y social. Así, propone la existencia de un inconsciente colectivo (Vogler, 2002). Los seres humanos tenemos la capacidad de establecer asociaciones y crear imágenes que prevalecen en la memoria de los pueblos. Esto constituye una herramienta empleada por los contadores de historias $y$, sobre todo, es un recurso del cual se valen los comunicadores y publicistas al momento de crear mensajes y también para acelerar los procesos de reconocimiento de perfiles, competencias e incumbencias de determinados actores. Entonces podemos señalar que la base del branding cultural se sustenta en los arquetipos y en los mitos como elementos de carácter simbólico:

Dichos componentes conforman parte del sedimento cultural al que los responsables de comunicación pueden acudir a la hora de construir una marca o narrar un relato en una pieza publicitaria que conecte de alguna forma con el público objetivo. (Fernández Gómez, et al. 2019, p. 117) 
Objetivos El presente trabajo de investigación se compone de dos objetivos genee hipótesis rales. El primero es estudiar cómo se define y comunica el perfil de un egresado de carrera de grado en diseño, en los portales de las universidades privadas argentinas. A su vez, contempla dos objetivos específicos: identificar características comunes entre los diferentes perfiles y orientaciones de las carreras de grado en diseño que se imparten en las universidades privadas argentinas; y por otro lado, determinar si los planes de estudio incorporan formación específica en gestión de negocios y emprendedurismo. El segundo objetivo general busca determinar qué modelo(s) arquetípico(s), según Mark y Pearson (2001), podría(n) contribuir a la construcción del estereotipo del diseñador-emprendedor.

Así, la hipótesis que se intentará comprobar en el estudio enuncia que las universidades privadas argentinas ofrecen sus carreras de grado en diseño con una figura estereotipada del licenciado, basada fundamentalmente en el perfil de un diseñador-emprendedor en contraposición al diseñador-científico.

Metodología Para determinar la muestra implicada en la hipótesis, fue necesario recopilar información sobre cuáles son las universidades privadas que imparten carreras de grado en diseño, reconocidas oficialmente por una Resolución Ministerial del Gobierno Nacional Argentino. De esta manera, se recurrió a la revisión de la base de datos de la Secretaría de Políticas Universitarias (Guía de Carreras Universitarias, s/f). Allí, se aplicaron los siguientes dos filtros: Nombre aproximado del título: "Diseño" y Estatal/Privado: "Privado". Esto arrojó un resultado de 85 carreras, de entre las cuales se extrajeron las que cumplían con los siguientes requisitos: Título: "licenciado en...", "diseñador..." y "profesor..."; Tipo de título: "grado"; Duración: "4 o 5 años". La muestra quedó conformada por 61 carreras de grado en diseño, que se impartían entre un total de 30 universidades privadas argentinas en enero del año 2020.

A continuación, se llevó adelante un análisis de contenido (realizado por un solo juez) que nos pudiera brindar los datos necesarios para luego realizar inferencias plausibles de reproducirse de forma válida y en contexto (Krippendorff, 1990). En este sentido, se definió como unidad de análisis a los sitios web de las carreras seleccionadas y se recopilaron los siguientes tipos de datos: universidad; facultad o departamento; titulación; complemento del título; rama, especialización y orientación; duración en años.

Posteriormente, se plantearon dos unidades de muestreo para sistematizar la información que específicamente se manifestara bajo un criterio en común. De esta manera, la Unidad de Muestreo 1 contempla el apartado de los sitios web donde se desarrolla el perfil del egresado. Aquí se recopilaron, en primer lugar, las palabras con las que se hace referencia al diseñador graduado - académico, científico, creativo, emprendedor, 
profesional-. En segundo lugar, se realizó una aproximación de análisis con categorías de corte cualitativo. En este sentido, tratando de identificar a qué "deseos o motivaciones humanas" se hace referencia, se emplearon las categorías de: estabilidad y control; riesgo y dominio; pertenencia al grupo y disfrute; independencia y realización, propuestas por Mark y Pearson (2001) como se aprecia en la Tabla 1. Por otra parte, se determinó a qué "categorías de necesidades y deseos" se alude -aportar estructura al mundo; anhelo del paraíso; dejar una huella en el mundo; conectar con otros- basados en la propuesta teórica de Fernández Gómez et al. (2019). Ver Figura 1.

La Unidad de Muestreo 2 contempla el apartado de los sitios web donde se presenta el plan de estudios. Aquí se recogieron los términos que dan cuenta de la presencia de asignaturas relacionadas con la investigación científica, asignaturas relacionadas con el emprendedurismo o gestión de proyecto personal/empresa, con el desarrollo de tesis y por último, con la práctica profesional.

Tabla 1. Arquetipos y motivación

\begin{tabular}{|l|l|l|l|l|}
\hline \multicolumn{5}{|c|}{ Archetypes and Motivation } \\
\hline Motivation: & $\begin{array}{l}\text { Stability \& } \\
\text { control }\end{array}$ & $\begin{array}{l}\text { Belonging \& } \\
\text { enjoyment }\end{array}$ & $\begin{array}{c}\text { Risk \& } \\
\text { mastery }\end{array}$ & $\begin{array}{l}\text { Independence } \\
\text { \& fulfillment }\end{array}$ \\
\hline & Creator & Jester & Hero & Innocent \\
\hline & Caregiver & $\begin{array}{l}\text { Regular Guy/ } \\
\text { Gal }\end{array}$ & Outlaw & Explorer \\
\hline $\begin{array}{l}\text { Costomer } \\
\text { Fear }\end{array}$ & $\begin{array}{l}\text { Financial ruin, } \\
\text { ill heath, } \\
\text { uncontrolled } \\
\text { chaos }\end{array}$ & $\begin{array}{l}\text { Exile, } \\
\text { orphaning, } \\
\text { abandonment, } \\
\text { engulfment }\end{array}$ & $\begin{array}{l}\text { Mowerless- } \\
\text { imposs }\end{array}$ & $\begin{array}{l}\text { Magician } \\
\text { out, } \\
\text { emptiness }\end{array}$ \\
\hline $\begin{array}{l}\text { Helps } \\
\text { People }\end{array}$ & Feel safe & $\begin{array}{l}\text { Have love/ } \\
\text { community }\end{array}$ & Achieve & $\begin{array}{l}\text { Find } \\
\text { hapiness }\end{array}$ \\
\hline
\end{tabular}

Fuente: Mark y Pearson (2001, p.18). 


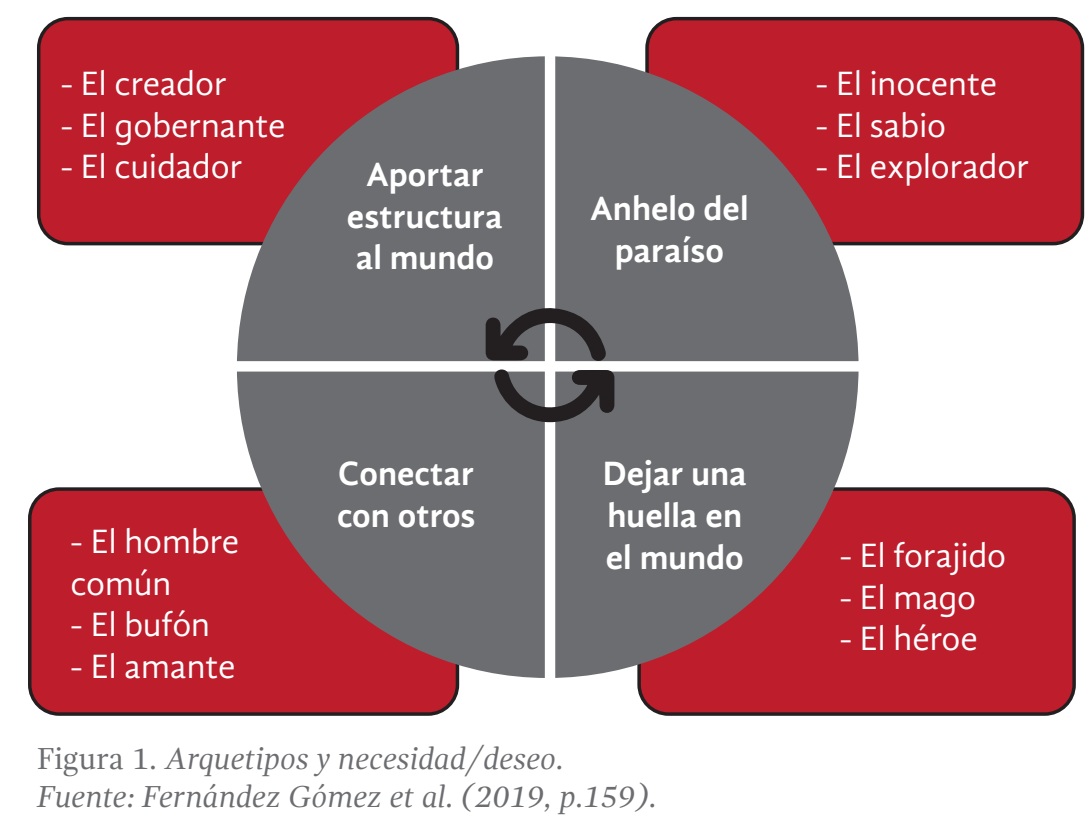

Resultados El 39\% de las carreras que se enmarcan en este estudio, están comprendidas en departamentos o facultades donde se emplea la palabra diseño en la nomenclatura. No existen en sí estructuras que sólo utilicen esta palabra, sino que siempre va acompañada de otras disciplinas como arquitectura (38\%); comunicación (26\%) y arte (13\%), entre otras. En principio, esto podría llamar la atención sobre una posible confusión en la concepción disciplinar de la palabra diseño por parte de los públicos, pero también es necesario tener en cuenta que las diferentes especializaciones pueden determinar la asociación a unos u otros campos de estudio.

Al contabilizar las ramas y especializaciones de estas carreras, nos encontramos con que $26.5 \%$ corresponde al diseño gráfico; $13.25 \%$ no lo contempla (no especifica rama o especialización); $11.75 \%$ corresponde al diseño de interiores, $10.3 \%$ al diseño industrial y $10.3 \%$ al de indumentaria. Por otra parte, $85.5 \%$ de las carreras implicadas en el estudio otorgan el título de Licenciado en Diseño (per se y con sus respectivas ramas o especializaciones) y $90 \%$ lo hace mediante planes de estudio estructurados en 4 años.

Respecto al perfil de los egresados publicado en los sitios web universitarios, como se puede visualizar en la Figura 2, los resultados arrojan una clara preponderancia en el uso de la palabra profesional para referirse a quienes obtienen este título; en segundo y tercer lugar se encuentran los términos creativo y emprendedor; por último (y en discrepancia con la titulación "Licenciado en...") las nomenclaturas académico o científico. 


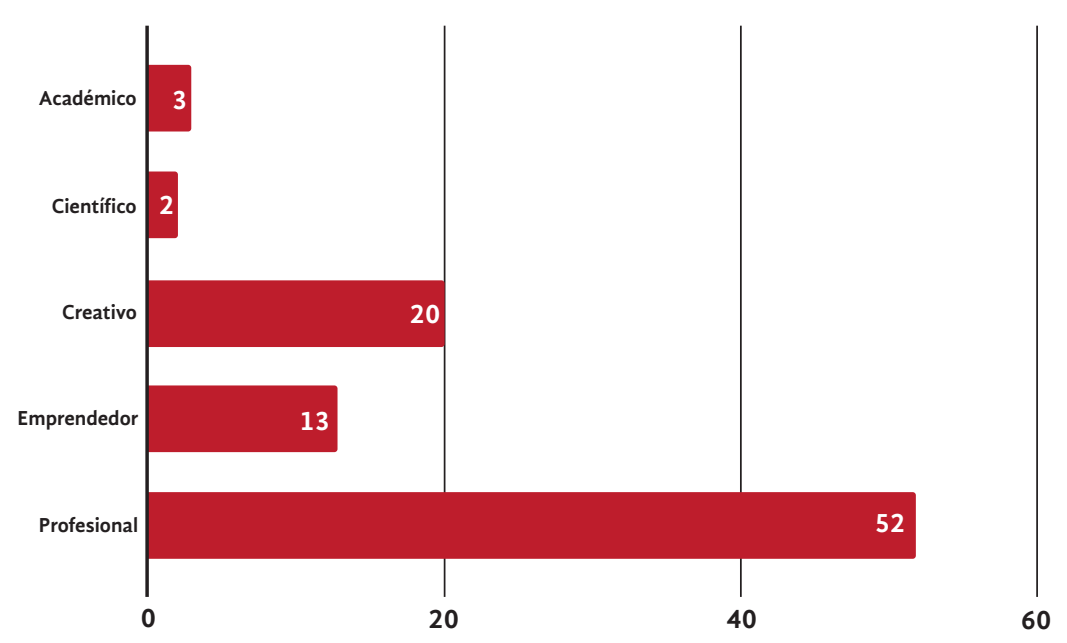

Figura 2. Términos que describen al diseñador en los perfiles de egreso analizados. Fuente: elaboración propia.

Por otra parte, en el análisis de los planes de estudio se halló una predominancia leve de asignaturas relacionadas al emprendedurismo o gestión de proyecto personal/empresa frente a materias específicas sobre metodología de investigación científica (ver Figura 3). En el mismo sentido, se observó una prevalencia más fuerte de asignaturas relacionadas con la práctica profesional frente al desarrollo de tesis. Se recuerda en este punto que el análisis contempla las palabras con las que se comunican las diferentes materias, no se analizaron los contenidos pedagógicos de las mismas, ya que este estudio se enfoca en el mensaje que se transmite a los públicos a través de las piezas comunicativas, en particular los sitios web de las carreras.

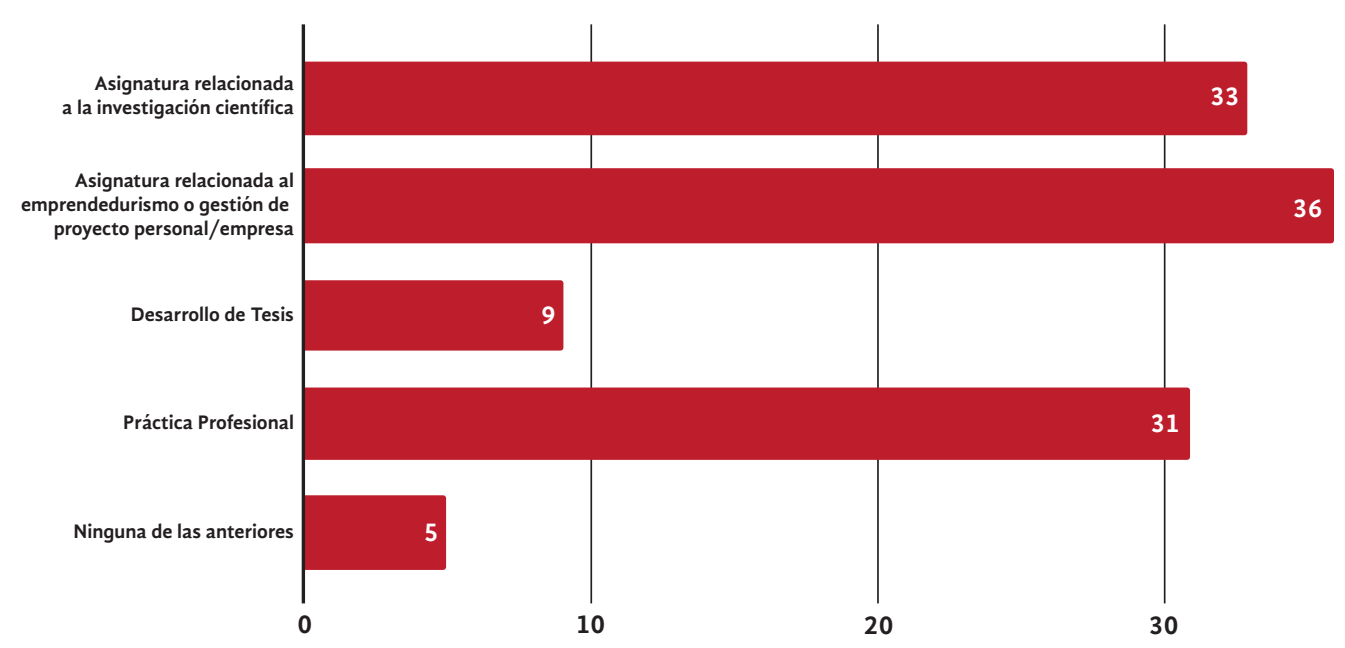

Figura 3. Asignaturas de los planes de estudio analizados.

Fuente: elaboración propia 


\section{Necesidades, motivaciones y deseos}

Consideramos el análisis de los deseos y motivaciones humanas como cualitativo, en tanto se han tratado de reconocer, en los textos que describen el perfil del egresado, relaciones con los conceptos teóricos de Mark y Pearson (2001). De esta manera, como puede apreciarse en la Figura 4, se obtuvo una predominancia de las categorías Estabilidad y control e Independencia y realización.

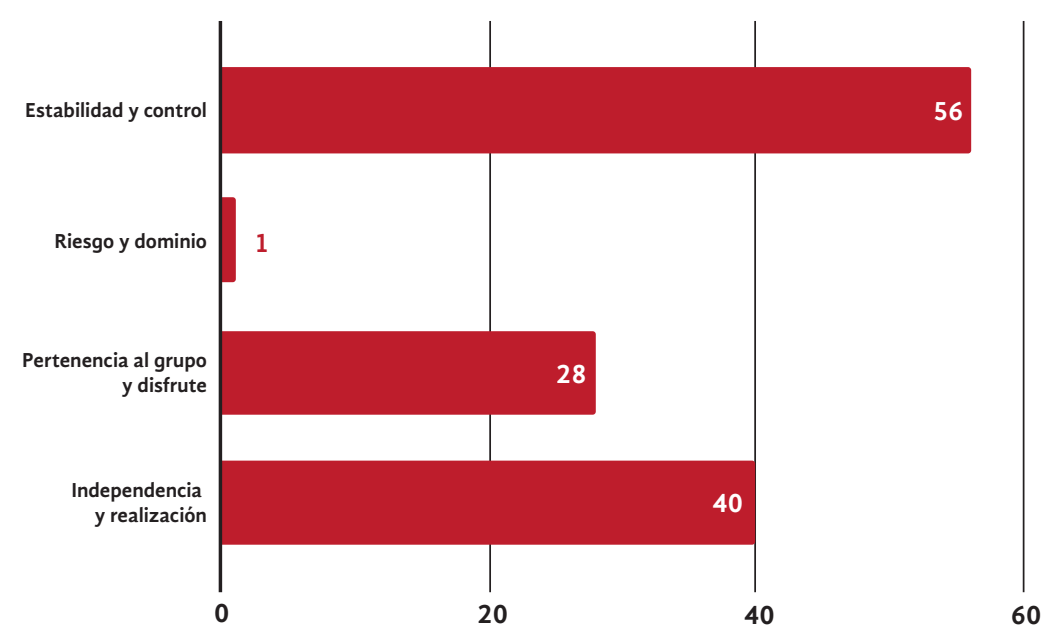

Figura 4. Deseos o motivaciones humanas identificadas en los perfiles de egreso analizados.

Fuente: elaboración propia.

A partir de estos resultados, y siguiendo la propuesta teórica de Mark y Pearson (2001), asociaremos las motivaciones estabilidad y control al arquetipo el creador e independencia y realización al arquetipo el sabio:

El creador. Deseo principal: crear algo de valor verdadero; Objetivo: darle forma a una visión; Miedo: tener una visión o ejecución mediocre; Estrategia: desarrollar control y talento artístico; Tarea: crear cultura, expresar la visión propia; Trampa: perfeccionismo, mala creación; Don: creatividad e imaginación. Lema: "Si puede ser imaginado, puede ser creado” (Fernández Gómez et al. 2019, pp. 166-167).

El sabio. Deseo principal: el descubrimiento de la verdad; Objetivo: usar la inteligencia y el análisis para entender el mundo; Miedo: ser engañado o embaucado, la ignorancia; Estrategia: buscar información y conocimiento, ser autorreflexivo y entender el proceso del pensamiento; Trampa: estudiar constantemente y no actuar; Don: sabiduría, inteligencia. Lema: "La verdad te hará libre”. (Fernández Gómez et al. 2019, pp.160-161) 
Para profundizar sobre las características de los arquetipos, también se recogieron huellas de las categorías de necesidades y deseos (Fernández Gómez et al. 2019) resultando que hay una correlación entre el arquetipo El creador y las huellas de Aportar estructura al mundo. El perfil del diseñador podría de esta forma adscribirse a las siguientes líneas:

\section{El creador sueña con, valga la redundancia, crear cosas nue- vas, innovar, embellecer su vida a través de nuevos proyectos, por eso se asocia con figuras como el artista, el escritor, el emprendedor o el inventor. Por ello, las marcas incentivan la creatividad, invitan a reinventarse y a expresar la personali- dad propia. (Fernández Gómez et al. 2019, p. 167)}

La categoría Conectar con otros, en tanto que habla de la conexión entre el diseñador y el comitente, las organizaciones y los colegas, ocupa un segundo lugar entre las huellas recogidas y sistematizadas. Se sitúa entre los ejes de Control y Pertenencia al grupo, pero no se corresponde con ninguno de los arquetipos propuestos (el hombre común, el bufón o el amante).

$\nabla$ Discusión

Hasta el momento, podemos expresar que se ha esclarecido una relación de implicación entre el estereotipo diseñador-emprendedor con el arquetipo El creador y, a su vez, entre diseñador-científico y El sabio. Lo que someteremos a discusión a continuación, es la relación de contrariedad entre diseñador-emprendedor y diseñador-científico. Y para esto, partiremos del análisis semiótico de la estructura elemental:

Existe, en primer lugar, una estructura elemental de la significación desde la cual se inicia también el recorrido generativo de la narración. Esta estructura puede considerarse como un modelo constitucional que especifica las formas que asumen las diferencias; es lo que constituye el famoso cuadrado binario de Greimas, que indica la forma elemental del significado mediante operaciones de opuestos. (Zecchetto, 2002, p. 221)

Lo que propone el cuadrado binario es la construcción de un sentido a partir de la relación entre los términos (ver Figura 5). Así, diseñador-emprendedor será contrario a diseñador-científico por relación de derivación; en tanto El creador es sub-contrario de El sabio. Las diagonales establecerán una relación contradicción, lo que significa que no pueden coexistir. 


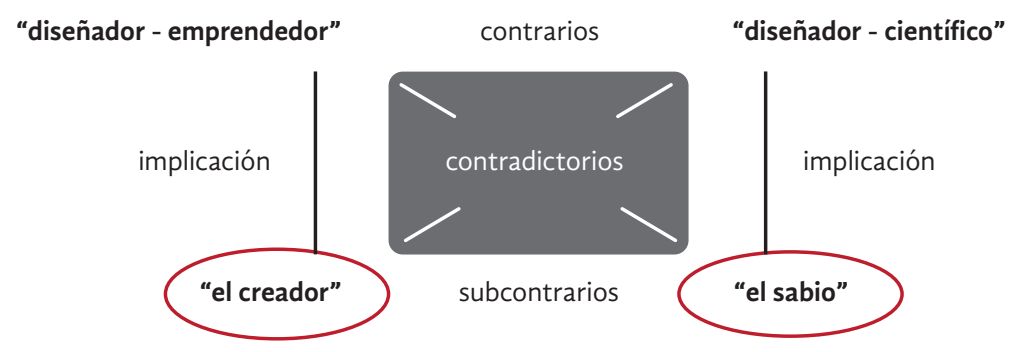

Figura 5. Adaptación del cuadrado binario

Fuente: elaboración propia basada en (Zecchetto, 2002).

A partir de aquí, se propone una segunda instancia de debate desde una campaña publicitaria titulada: Te formás vos, cambiás el mundo (2018) de la Universidad Empresarial Siglo 21 (institución que formó parte del estudio). La misma fue seleccionada de forma intencional, es decir, de modo arbitrario en tanto que, a juicio experto del investigador, presenta características de relevancia para la discusión (Sabino, 2002): se trata una campaña contemporánea, de una universidad privada en la República Argentina, que propone diferentes modelos aspiracionales entre los que se encuentra una estudiante de diseño junto a otros alumnos de carreras diferentes.

En el spot publicitario Te formás vos, cambiás el mundo | Universidad Siglo 21 (Universidad Siglo 21, 28 de enero de 2018) se muestra una seguidilla de fragmentos de historia de vida de diferentes personas. Desde el comienzo del día, el inicio de una rutina, se ancla la idea de que "un mundo mejor es posible", y es posible debido a que las personas son quienes lo crean. Se interpela a la audiencia con un lenguaje directo, inclusivo ("nuestro momento de tomar decisiones, de animarnos, de generar (ambios"). Todas estas características que son propias del arquetipo El creador, también se ilustran con imágenes de la cultura popular (como la caracterización del afiche We can do it! ${ }^{3}$ ): se va presentando a los protagonistas, en su ambiente y jornada de estudiante, haciendo un paralelismo con dichas imágenes que forman parte del inconsciente colectivo.

\section{La finalidad de la dramatización y el arquetipo es mostrar un ejem- plo (creíble) con el fin de potenciar la identificación del especta- dor con el protagonista de la ilustración ofrecida y modificar así su conducta. Si se le cuenta una historia (portadora de valores) con un escenario y actor reconocibles, se facilita y acelera el proceso de empatía entre el espectador [...] y el protagonista de la historia. (Rey, 2006, pp. 83-84)}

En el mismo sentido, la frase "tenemos la actitud que tienen los que construyen el destino" enfatiza aún más la idea de la creación. La creación

\footnotetext{
${ }^{3}$ Se presenta a una de las alumnas vistiendo y posando de la misma manera que la mujer del conocido cartel de propaganda australiana (lanzado durante la Segunda Guerra Mundial) diseñado por J. Howard Miller en 1943 para Westinghouse Electric.
} 
a partir de la formación y el cambio en la estructura del mundo, como resultado final de esa evolución personal.

Además de lo discursivo, en este spot principal se pueden establecer otras relaciones de intertextualidad. El audiovisual, como se mencionó anteriormente, es interpretado por diferentes personajes en su rol de estudiantes y a la vez hacedores. Si bien se podría intuir la carrera que estudiaría cada uno de ellos a partir de ciertas convenciones estereotipadas, a la par de este comercial se difundieron los testimonios de cada uno de los actores y actrices (estudiantes y egresados reales de la universidad en cuestión) donde cuentan su experiencia personal.

Así conocemos a una alumna de la carrera de Diseño de Indumentaria y Textil (único caso de estudiante de diseño en toda la campaña), a quien en su video Testimonio | Natsue Kiyama, alumna Siglo 21 (Universidad Siglo 21, 2 de febrero de 2018), se la presenta explícitamente como "Emprendedora en Diseño Inclusivo". Lo interesante, más allá del relato que narra la protagonista, es ver cómo se la representa en el primer spot a la par de otros estudiantes de otras carreras. Al menos en tres oportunidades la podemos reconocer: retratada en su rutina diaria (despertando por la mañana, en su habitación) [min. 0:04]; de alguna manera idealizada, es decir, la forma en que podemos imaginar al creativo como algo ideal, ficticio o mítico (con un par de alas ilustradas) [min. 0:25] y en su entorno de trabajo: creando (vistiendo maniquíes con telas blancas) [min. 0:38].

Conclusiones En la actualidad y en el contexto de las universidades privadas en Argentina, podemos decir que las carreras de grado en diseño otorgan un título oficial (con reconocimiento del Ministerio de Educación de la Nación) y esto habilita para el ejercicio profesional, en tanto se encuentran dentro del grupo de profesiones no reguladas. En su mayoría son licenciaturas, cuyo perfil y alcance son definidos por las propias casas de altos estudios.

¿Qué implicancias tiene esto? Principalmente, una variedad de ramas, especializaciones y enfoques que abordan el saber, saber hacer y saber ser de maneras particulares. A través del presente estudio hemos identificado patrones comunes que se inscriben en un entorno socioeconómico neoliberal. En este sentido, el enfoque empresarial es trasladado a todas las formas de representación y persuasión de las instituciones educativas. Así, naturalizamos la inscripción de las prácticas de enseñanza/aprendizaje basadas en competencias, donde el espíritu emprendedor es considerado fundamental para el desarrollo del saber ser: el establecer conexiones con los otros para desenvolvernos en una sociedad (de consumo). 
Al mismo tiempo, entendemos la necesidad de las universidades de comercializar sus carreras y sus perfiles profesionales mediante la comunicación publicitaria, siempre en consonancia con una ideología mercantilista. Para esto, se basan en la utilización de figuras arquetípicas que permiten al público empatizar con el mensaje y construir su identidad basada en esta ideología compartida (Douthwaite, 2008; Hernández-Santaolalla, 2019).

Con esto reconocemos que la publicidad siempre propone un discurso que está provisto de una fuerte carga significativa y que, al mismo tiempo, tiene la capacidad de fagocitarlo todo (Screti, 2012). Una campaña que se titula "Un mundo mejor es posible", neutraliza el cambio social, lo reduce a la voluntad vinculada a la meritocracia y la superación personal, cuando lo que se está publicitando es una carrera que prepara a sus estudiantes para los negocios en el marco de una universidad que en definitiva también es una empresa.

En este contexto es que entendemos que en las comunicaciones web de las instituciones privadas se da lugar al desarrollo de un perfil del diseñador-emprendedor en contraposición al diseñador-científico. Los textos refieren en su mayoría al licenciado en Diseño como un profesional, un emprendedor o un creativo, características que podemos enmarcar dentro del arquetipo El creador, que sabemos parte del inconsciente colectivo. enfoque de la educación en competencias. España: Dirección General de Políticas Educativas y Ordenación Académica del Principado de Asturias.

Devalle, V. (2008). Las carreras de diseño en las universidades argentinas, una historia de los comienzos. Reflexión Académica en Diseño y Comunicación $N^{\circ}$ IX, Vol. 9 (9), 128-129. Recuperado de: https://fido.palermo. edu/servicios_dyc/publicacionesdc/vista/detalle_articulo.php?id_libro=123\&id_articulo=1051 [Consultado por última vez el 17 de febrero de 2020].

Douthwaite, J. (2008). Gender and ideology in advertising. En G. Garzone \& S. Sarangi (Eds.), Discourse, Ideology and Specialized Communication (pp.277-310). Berna: Peter Lang.

Fernández Gómez, J., Rubio-Hernández, M. y Pineda, A. (2019). Branding cultural: una teoría aplicada a las marcas y a la publicidad. Barcelona: Editorial UOC.

Greimas, A., y Fontanille, J. (2002). La semiótica de las pasiones ([2a ed.]). México: Siglo Veintiuno. (Trabajo original publicado en francés en 1991). 
Hernández-Santaolalla, V. (2019). Advertising discourse and 'new' ideologies in Spain. En: R. Yilmaz (Ed.), Handbook of Research on Narrative Advertising (pp.96-107). Hershey, PA: Business Science Reference.

Krippendorff, K. (1990). Metodología de análisis de contenido: teoría y práctica. Barcelona: Paidós.

Ley $N^{\circ} 24.521$ de 1995. Disposiciones preliminares. Educación Superior. Educación superior no universitaria. Educación superior universitaria. Disposiciones complementarias y transitorias, 20 de julio de 1995. Recuperado de: http://servicios.infoleg.gob.ar/infoleglnternet/anexos/25000-29999/25394/texact.htm [Consultado por última vez el 17 de febrero de 2020].

Ley N²6.002 de 2004. Educación Superior. Régimen de Títulos. Modificación de la Ley No 24.521. 16 de diciembre de 2004. Recuperado de: http://servicios.infoleg.gob.ar/infoleglnternet/anexos/100000-104999/102596/ norma.htm [Consultado por última vez el 17 de febrero de 2020].

Mark, M. y Pearson, C. S. (2001). The Hero and the Outlaw: Building Extraordinary Brands Through the Power of Archetypes. Nueva York: McGrawHill.

Marquina, M. (2004). Panorama de las titulaciones en el Sistema de Educación Superior argentino: Aportes para un estudio comparado. Buenos Aires: Comisión Nacional de Evaluación y Acreditación Universitaria. Recuperado de: http://www.coneau.gob.ar/archivos/1333.pdf [Consultado por última vez el 17 de febrero de 2020].

Ramos, C. (2017). Los paradigmas de la investigación científica. Avances En Psicología, 23(1), 9-17. DOI: https://doi.org/10.33539/avpsicol.2015. v23n 1.167

Recomendación del Parlamento Europeo y del Consejo de 18 de diciembre de 2006 sobre las competencias clave para el aprendizaje permanente (2006/962/CE). Diario Oficial de la Unión Europea, L 394/10. Bruselas, 18 de diciembre de 2006. Recuperado de: https://eur-lex.europa.eu/legal-content/ES/TXT/HTML/?uri=CELEX:32006H0962\&from=EN [Consultado por última vez el 17 de febrero de 2020].

Rey, J. (2006). Publicidad y religión. Semejanzas y diferencias entre el discurso publicitario y el discurso católico. Trípodos, 18, 65-94.

Sabino, C. (2002). El proceso de investigación. Venezuela: Editorial Panapo.

Scotto, S. C. (2004). Apuntes para una defensa de la universidad pública. Cuadernos de Educación, 3(3), 11-19. Recuperado de: https://revistas.unc. edu.ar/index.php/Cuadernos/article/view/668 [Consultado por última vez el 17 de febrero de 2020].

Screti, F. (2012). Publicidad en la política, política en la publicidad. Pensar La Publicidad. Revista Internacional De Investigaciones Publicitarias, 6(1), 3561. DOI: https://doi.org/10.5209/rev_PEPU.2012.v6.n1.38655 
Secretaría de Políticas Universitarias. Departamento de Información Universitaria. (s/f). Guía de Carreras Universitarias. Recuperado de: http://guiadecarreras.siu.edu.ar/ [Consultado por última vez el 17 de febrero de 2020].

Universidad Siglo 21. (28 de enero de 2018). Te formás vos, cambiás el mundo | Universidad Siglo 21.[Archivo de video]. Youtube. https://youtu.be/ auW6Im0X3zE [Consultado por última vez el 17 de febrero de 2020].

Universidad Siglo 21. (2 de febrero de 2018). Testimonio | Natsue Kiyama, alumna Siglo 21.[Archivo de video]. Youtube. https://youtu.be/K_ffKnR60WU [Consultado por última vez el 17 de febrero de 2020].

Vogler, C. y Conde, J. (2002). El viaje del escritor. Barcelona: Robinbook.

Zecchetto, V. (2002). La Danza de los Signos: Nociones de semiótica general. Quito-Ecuador: Ediciones Abya-Yala.

Sobre el autor Jonathan Alexis Taibo

Máster en Comunicación y Cultura por la Universidad de Sevilla, España. Licenciado en Diseño de Comunicación Visual por la Universidad Nacional de Rosario, Argentina. Administrador de Empresas de Diseño y Diseñador Gráfico y Publicitario por el Colegio Universitario IES Siglo 21, en Córdoba, Argentina. Colaboró con la Secretaría Técnica de la Red DiSUR durante los años 2016 y 2017, formando parte, además del equipo organizador del Tercer Congreso Latinoamericano de Diseño (Rosario, Argentina) y del equipo de contenidos web de la cuarta edición del mismo evento académico (Mendoza, Argentina). Desde el año 2020, es asistente honorario en el departamento de Comunicación Audiovisual y Publicidad de la Facultad de Comunicación de la Universidad de Sevilla. Se desempeña como profesional independiente desde el año 2015 en Argentina y actualmente, en España. 